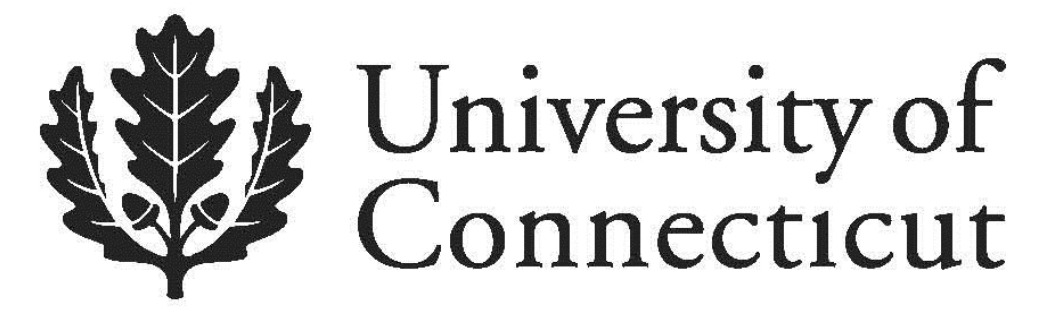

Department of Economics Working Paper Series

\title{
Measuring U.S. Business Cycles: A Comparison of Two Methods and Two Indicators of Economic Activities
}

\author{
Francis W. Ahking \\ University of Connecticut
}

Working Paper 2013-10

May 2013, Revised June 2014

365 Fairfield Way, Unit 1063

Storrs, CT 06269-1063

Phone: (860) 486-3022

Fax: (860) 486-4463

http://www.econ.uconn.edu/

This working paper is indexed on RePEc, http://repec.org 
Measuring U.S. Business Cycles: A Comparison of Two Methods and Two Indicators of Economic Activities

\author{
By \\ Francis W. Ahking \\ Associate Professor \\ Department of Economics \\ The University of Connecticut \\ Storrs, CT 06269-1063 \\ e-mail: francis.ahking@uconn.edu \\ Telephone: 860 486-3026 \\ (Revised draft. Please do not quote.) \\ JEL Classification: E32, E37
}

\title{
(ABSTRACT)
}

In this paper, we examine two issues concerning business cycle research. First, a number of studies have demonstrated that more complicated non-linear models do not replicate business cycle features better than simpler linear models. In Harding and Pagan (2002), they showed that a random walk with drift model of real GDP for the U.S., U.K., and Australia can capture the main business cycle features of the respective countries quite well. Adding non-linear structure, such as Hamilton's (1989) Markov-switching model produced cycles that are too extreme, especially with respect to the cumulative movements of the cycles, where cumulative movements are a measure of cumulated output losses from peak to trough of a business cycle. Furthermore, Harding and Pagan (2003a) argued that based on criteria, such as simplicity, transparency, robustness, and replicability, the non-parametric Bry and Boschan algorithm (1971) is in fact superior to the Markov-switching model in determining turning points in business cycles. Similarly, Hess and Iwata (1997) showed that a non-linear models such as the Markov-switching models are no better than a simple ARIMA $(1,1,0)$ model in replicating business cycle features.

We start by comparing how well the Hamilton's Markov-switching model and the Bry and Boschan algorithm can replicate the U.S. business cycle features. One interesting finding that has not been shown before is that we are unable to replicate Hamilton's original result for the same sample period using real GDP rather than real GNP as Hamilton did. Furthermore, we also found that Hamilton's Markov-switching model is not robust with respect to different sample periods. The Bry and Boschan algorithm, on the other hand, replicated business cycle features consistently.

Second, Burns and Mitchell (1946) and NBER's Business Cycle Dating Committee suggested that a variety of time series representing economic activities should be used for the purpose of dating business cycle.

Nevertheless, real GDP is by far the most popular and frequently used single series to represent aggregate economic activities in business cycle research. We compared the ability of the U.S. real GDP and a coincident index published by the Federal Reserve Bank of Philadelphia in replicating features of the U.S. business cycle. We found that a constructed quarterly version of the coincident index is slightly preferred over the real GDP, suggesting that the coincident index may be a better indicator than the commonly used real GDP as an overall indicator of U.S. economic activities. 
I. Introduction

Since the publication of Burns and Mitchell's (1946) seminal work on measuring business cycles, it has remained an active area of macroeconomic research. Examples of some recent research using various empirical methodologies include Kim and Nelson (1998), Mejía-Reyes (2004), Krolzig and Toro (2005), Mönch and Uhlig (2005), Proietti (2005), McAdam (2007), Bruno and Otranto (2008), and Schirwitz (2009), among many more other research. In the literature, there are two different but related concepts of the business cycle. Burns and Mitchell's (1946) research on business cycles has become known in the literature as the classical business cycles. In a classical business cycle, a recession is always associated with negative growth, i.e., an absolute decline in the level of aggregate economic activity. Similarly, an expansion is characterized by periods of positive growth, i.e., an absolute increase in the level of aggregate economic activity. The other business cycle concept is known as the growth cycle. In a growth cycle, an economy can be classified as being in a downturn even when it is experiencing periods of positive growth, but economic activity is below some underlying growth trend, giving rise to what is known as a growth recession. We focus only on the classical business cycle in this paper and discuss two unresolved issues. One issue concerns the best statistical method to extract business cycle phases from a given data series. Another issue, which has received relatively little or no attention, is whether or not the commonly used real GDP is the best data series to represent aggregate economic activity of a country. We'll discuss further these two issues and the main objectives of our paper in the next section, Section II. Sections III and IV present the empirical results of comparing the performance of Hamilton's (1989) Markov switching (MS) Model and Bry and Boschan's (1971) computer algorithm (BB algorithm) in replicating U.S. business cycle features, respectively. In Section V, we compare a coincident index, published by the Federal Reserve Bank of Philadelphia, to the real GDP to determine which series is a better indicator of aggregate U.S. economic activity. Our summary and conclusions are in Section VI. To summary our results briefly, we find that the BB algorithm is better than the Hamilton's MS model in replicating U.S. business cycle features. We also find that the coincident index is slightly preferred over the real GDP as a single indicator of aggregate economic activity. 


\section{Determining business cycle turning points}

In the U.S., the private non-profit National Bureau of Economic Research Business Cycle Dating Committee (henceforth NBER Committee) determines and announces business cycle turning points (NBER chronology). The determination of these turning points closely follows the methodology of Burns and Mitchell (1946). Although not official and can sometimes arouse controversies, the NBER chronology is nevertheless widely accepted and frequently regarded as the standard for comparison. Researchers, however, have also developed other statistical models to identify business cycle turning points. Boldin (1994), and Massmann, Mitchell, and Weale (2003) provided surveys of various statistical models for determining business cycle turning points. These statistical models are especially useful for international comparison of business cycles where it is important that business cycle turning points are determined on a uniform basis, and in countries where no comparable agency such as the NBER is available to provide business cycle turning points. ${ }^{1}$ Among the statistical models, Hamilton's (1989) MS model proves to be very popular. The appeal of the MS model is that it is a non-linear model since it treats recession and expansion asymmetrically. A number of studies, however, have shown that the more complicated parametric non-linear models do not replicate business cycle features better than the simpler linear models. For example, in Harding and Pagan (2002), they showed that a random walk with drift model of the real GDP for the U.S., U.K., and Australia can capture the main business cycle features of the respective countries quite well. Adding non-linear structure such as Hamilton's (1989) MS model produced cycles that are too extreme, especially with respect to the cumulative movements of the cycles, where cumulative movements are a measure of cumulated output losses from peak to trough of a business cycle. Furthermore, Harding and Pagan (2003a) argued that based on criteria, such as simplicity, transparency, robustness, and replicability, the simpler non-parametric BB algorithm is superior than MS models in determining turning points in business cycles. ${ }^{2}$ Similarly, Hess and Iwata (1997) showed that non-linear models such as the MS models are no better than a simple ARIMA $(1,1,0)$ model in replicating business cycle features. On the other hand, Krolzig and Toro (2005), while acknowledging that the MS models of the type proposed by Hamilton are only able to capture some of the stylized facts of business cycles, they disputed the conclusions of Harding and Pagan (2002, 2003a), however. They argued that structurally 
richer MS models such as the Markov-switching VAR models can replicate also all the stylized facts in their study of the European business cycles. ${ }^{3}$

The statistical models surveyed by Boldin (1994), and Massmann, Mitchell, and Weale (2003) examined the effectiveness of various statistical models in determining business cycle features. The models are mostly parametric models. A very popular non-parametric approach is the BB algorithm which is a computer program designed to replicate the decision making process of the NBER Committee in an automatic way, ${ }^{4}$ thus avoiding some of the criticisms faced by the NBER Committee. These criticisms include a lack of transparency on the part of the NBER Committee, and the potential for inconsistency in the decision outcomes when memberships on the NBER Committee change over time. The popularity of the BB algorithm stems from its ability to closely replicate the NBER's chronology. It is curious that while there are a number of studies into the effectiveness of the various statistical models in determining business cycle features, few studies have looked at how well the BB algorithm does in comparison to other statistical models in replicating business cycle features. In the next section, we compare Hamilton's MS model to the BB algorithm ${ }^{5}$ to determine how well they replicate business cycle features. ${ }^{6}$

The second objective of this paper is to compare a coincident index published by the Federal Reserve Bank of Philadelphia to the real GDP to determine which one is a better single indicator of aggregate economic activity. Burns and Mitchell (1946) defined business cycles as fluctuations in aggregate economic activity but they provide no indication of how aggregate economic activity could be measured. However, they wrote on p. 72 that "Aggregate activity can be given a definite meaning and made conceptually measureable by identifying it with gross national product at current prices.” But, noting that it is better to include only the portion of the national product that passes through the "market" for the purpose of measuring cycles, they concluded on p. 73 that “... no satisfactory series of any of these types is available by months or quarters for periods approximating those we seek to cover." Instead, they suggested the use of a variety of series for the purpose of dating business cycles. The NBER Committee also does not rely on a single series to date business cycle turning points. According to the Committee, “... a recession is a significant decline in economic activity spread across the economy, lasting more than a few months, normally visible in real GDP, real income, employment, industrial production, and wholesale-retail sales."” Nevertheless, since the real GDP has been shown to be able to replicate many features of the business cycle 
quite well, it has become the most popular and commonly used quarterly series of aggregate economic activity. See for example, Hamilton (1989), Harding and Pagan (2003a) for the use of the U.S. real GDP, McAdam (2007) for the use of the U.S., Japan, and the Euro area real GDP, and Schirwitz (2009) for the use of the German real GDP.

The Federal Reserve Bank of Philadelphia now publishes a monthly coincident index for the U.S. and the 50 states. This index has several desirable properties when compared to the real GDP. First, the index is consisted of four indicators. This is consistent with the philosophy of Burns and Mitchell (1946) and NBER's Committee that co-movements of several indicators are important in determining business cycle turning points. Second, the index is available on a more timely monthly frequency than the quarterly availability of the real GDP. ${ }^{8}$ Crone (2006), and Crone and Clayton-Matthews (2005) suggested that this index can be used to represent aggregate U.S. economic activity. There are relatively few studies that have examined the usefulness of this index as an indicator of U.S. aggregate economic activity, however.

Furthermore, it is not clear what criteria are to be used when evaluating this coincident index. In Section IV of this paper, we compare this coincident index to the real GDP in determining business cycle phases.

Throughout this paper, we use NBER's chronology as the benchmark for comparison. The criteria that we use for comparison include dating turning points, duration, and an index of concordance, which measures the percentage of time two series are in the same phase of a business cycle. This will be explained further in the next section.

III. The Markov switching model

We start with a brief review of Hamilton's MS model. A MS model with $m$ states for output growth can be represented as:

$$
\Delta y_{t}=\mu\left(s_{t}\right)+\sum_{i=1}^{k} \phi_{i}\left[\Delta y_{t-i}-\mu\left(s_{t-i}\right)\right]+e_{t},
$$

where $\mu\left(s_{t}\right)$ is the mean growth rate in state $s_{t}, \phi_{i}(i=1, \ldots k)$ denotes autoregressive parameter, $e_{t} \sim N\left(0, \sigma^{2}\right)$ is the error term. In Hamilton's empirical model, he considered only two states, i.e., $m=2$, namely recession (state $0, s_{t}=0$ ), and expansion (state 1, $s_{t}=1$ ). The key feature of the MS model is the assumption that the realization of the states, $s_{t}=0$ or $s_{t}=1$ is unobservable, but the transition between states is governed by a first-order Markov process: 
$\operatorname{Prob}\left[s_{t}=1 \mid s_{t-1}=1\right]=p, \operatorname{Prob}\left[s_{t}=0 \mid s_{t-1}=1\right]=1-p, \operatorname{Prob}\left[s_{t}=0 \mid s_{t-1}=0\right]=q$, and $\operatorname{Prob}\left[s_{t}=1 \mid s_{t-1}=0\right]$

$=1-q$.

In column (1) of Table 1, we reproduced Hamilton's original results from his Table 1, (1989, p.

372). The change in the natural logarithmic of quarterly real GNP in constant 1982 dollars was used to

represent the U.S. economy. A fourth-order autoregressive process was used to approximate the stochastic

process of the growth of real GNP. The sample period was 1951:I - 1984:IV. Because of first-differencing and four lags were used to approximate the stochastic process of the first-differenced real GNP, the actual sample was 1952:II - 1984:IV. In Table $1, \alpha_{0}$ is the maximum likelihood estimate of the quarterly growth rate during recession (state 0 ); $\alpha_{1}$ is the maximum likelihood estimate of the quarterly growth rate during expansion (state 1). As discussed above, $p$ is the probability of the economy remaining in state 1once it is in state $1 ; q$ is the probability of the economy remaining in state 0 once it is in state $0 ; \sigma$ is the estimate of the standard error of the equation, and $\phi_{1} \ldots \phi_{4}$ are the maximum likelihood estimates of the four lags of the first-differenced of real GNP. Finally, $E\left(D_{R}\right)=(1-q)^{-1}$ is the expected duration of a recession, and $E\left(D_{E}\right)=(1-p)^{-1}$ is the expected duration of an expansion.

In column (2) of Table 1, we replicated Hamilton's equation using the same real GNP data for the same sample period. ${ }^{9}$ We do this to ensure that any differences in results are not the results of using different software or estimation method. Our estimates are almost identical to Hamilton's, but are identical to Table 22.1 in his 1994 book. Our estimate of $\alpha_{1}(1.164)$ is the only one that deviates from Hamilton's original estimate of 1.522. Our estimate, however, has a lower asymptotic standard error. We are quite confident therefore that any subsequent differences in estimating the MS model cannot be attributed to the use of different computer software or program.

Column (3) of Table 1 shows the results of replicating Hamilton's original equation for the same sample period as the Hamilton's, but substituting real GDP in constant 2005 chained dollars for real GNP. ${ }^{10}$ Surprisingly, there are several notable differences. Notably, the average negative growth rate during recession of $-1.034 \%$ per quarter is greater (in absolute value) than the average negative growth rate of $0.358 \%$ obtained by Hamilton using real GNP, suggesting a much steeper decline during a recession than Hamilton's original estimates. The second notable difference is that the estimate of $q$, which is the 
probability that the economy remains in a recession next period given that it is in a recession this period, is much smaller than Hamilton's estimate and it is no longer statistically significant. Finally, with real GNP data, lags 3 and 4 of the growth rate of real GNP are statistically significantly different from zero. Using real GDP data, however, only lag 1 is statistically significantly differently from zero.

Table 1, column (4) presents the results of estimating Hamilton's original specification using real GDP data for 1948:I - 2011:III. The results are closer to those estimated with real GDP (column (3)) for sample period 1951:1 - 1984:IV than Hamilton's results in column (1). Again, the average negative growth rate of $-1.310 \%$ per quarter during recession is greater (in absolute value) than the average negative growth rate obtained by Hamilton. The probability that the economy stays in recession next period given that it is in a recession this period is again smaller than Hamilton's estimate. We observe that there is a change in the stochastic process generating the growth of real GDP for this sample period. Now, the first three lags are statistically different from zero at the $5 \%$ significant level, which is quite different from the shorter sample in column (3) where only the first lag is statistically different from zero at the $5 \%$ significant level. $^{11}$

In Table 2, we present the business cycle turning points determined by the various methods and models. In column (1), we reproduced the NBER's chronology for 1951:I - 1984:IV for ease of comparison. ${ }^{12}$ Column (2) is reproduced from Hamilton's Table II (1989, p. 374). As discussed in Hamilton, the turning points for recessions are determined by when the probability of a recession is greater than $50 \%$, where the probability is estimated using full-sample information, termed full-sample smoother by Hamilton. A comparison of Hamilton's turning points and the NBER's chronology, especially the differences between them, can also be found in Hamilton (1989, p. 374). Briefly, and assuming that difference in one quarter is not significant, Hamilton's turning points are broadly consistent with the NBER's chronology. Column (3) of Table 2 reports the turning points determined from the replicated regression using the same methodology as Hamilton's. Given how closely our replicated estimates match that of Hamilton's, it is not at all surprising that the turning points determined from the replicated regression also match closely to those of Hamilton's, where differences are no more than one quarter.

Using the full-sample smoother, we are unable to find any meaningful turning points from our MS model estimated with real GDP rather than with real GNP for 1951:I - 1984:IV, however. For example, 
there are only four quarters for which the probability of a recession is greater than 50\%. They are 1958:I, 1970:IV, 1980:II, and 1981:II. This result is rather surprising since the correlation coefficient between real GDP and real GNP is 0.99 for this sample period, and the correlation coefficient for the growth rates of real GDP and real GNP is $0.94 !^{13}$ Similarly, we find very disappointing results when we use the full-sample smoother to determine business cycle turning points for the longer sample period 1948:I - 2011:III using the MS model estimated with real GDP. We find the following quarters to have a probability of a recession of greater than 50\%: 1949:IV, 1958:I, 1970:IV, 1980:II, 1981:II, 1981:IV - 1982:1, and 2008:IV - 2009:I. Again, these are not very meaningful turning points.

All in all, our results from Hamilton's MS models are consistent with the observations made by Harding and Pagan (2003a) and also by many other researchers that, as a statistical model of the business cycle, Hamilton's MS model is very model and sample specific. We are able to demonstrate that Hamilton's MS model is not robust with respect to the sample period. What is more surprising is that Hamilton's MS model is not robust to a slight change in data as we have also demonstrated when we substituted real GDP for real GNP in our estimation of the MS model even-though these two series are highly correlated both in levels and growth rates. To our knowledge, this has not been demonstrated before in the literature.

IV. The Bry and Boschan algorithm

Before we discuss the results of dating business cycle turning points using the BB algorithm, we will start with a brief description of some of the features of the BB algorithm, interested readers can find the technical details in Bry and Boschan (1971). (a) The BB algorithm is developed for use with monthly data. Harding and Pagan (2002), however, have provided a modification to the original BB algorithm for use with quarterly data. ${ }^{14}$ (b) The minimum cycle length (peak to peak or trough to trough) has to be at least 15 months. (c) Each phase of a cycle (peak to trough or trough to peak) has to be at least 5 months long. (d) Peaks and troughs have to alternate. If there are consecutive peaks (troughs), the highest (lowest) value is chosen. (e) Turning points within 6 months of the beginning or end of the series are eliminated. Furthermore, the first turning point, measured from the beginning or the end of the series, has to be higher (for a peak) or lower (for a trough) than the respective end-point values. 
Column (4) of Table 2 reports the results of using the BB algorithm and real GNP (BB-RGNP) to determine business cycle turning points. ${ }^{15}$ The real GNP data are the same data used by Hamilton for the sample period 1951:I - 1984:IV, which we have also used earlier in our replicated MS model. The biggest difference is that the BB-RGNP failed to find the turning points for the recession of 1980:I - 1980:III (NBER's chronology). This is in contrast to both the results obtained by Hamilton and by our replicated the MS model. This suggests that the BB algorithm is less satisfactory than Hamilton's MS model in finding turning points in this sample period and using real GNP. The results are rather different, however, using the BB algorithm and real GDP (BB-RGDP) reported in column (5) of Table 2. The turning points determined are generally consistent with the NBER's chronology with two exceptions. In both cases, BBRGDP determined shorter recessions for 1969:III - 1970:I, and again for the recession of 1981:III - 1982:I when compared to NBER's chronology of 1969:IV - 1970:IV and 1981:III - 1982:IV. Moreover, BBRGDP's recessions of 1957:III - 1958:I, 1969:III - 1970:I, and 1981:III - 1982:I, are all shorter than the corresponding recessions obtained by Hamilton's MS model. Thus, while we are unable to obtain meaningful turning points estimating Hamilton's MS model using real GDP data, we are able to obtain turning points that are consistent with NBER's chronology using the BB algorithm. Finally, while BBRGDP correctly identified the recession of 1980:I - 1980:III (NBER's chronology) but this was missed by BB-RGNP, again suggesting that although real GNP and real GDP are highly correlated, there is sufficient difference between these two series that the BB algorithm produced slightly different results for them. ${ }^{16}$

Table 3 reports cycle duration in quarters, average duration in quarters (in parenthesis) calculated from the turning points reported in Table 2. The average recession found by using BB-RGDP is the shortest, while the average recession found by using our replicated MS model is the longest. All the other average duration of recessions are within one quarter of NBER's chronology, however. The average duration of expansion is the longest for BB-RGNP, not surprisingly since it missed the recession of 1980:I - 1980:III (NBER's chronology). This also makes the average duration of a complete cycle, measured either from trough to trough, or from peak to peak, the longest for BB-RGNP. Otherwise, the average duration of expansions, the average duration of a complete cycle from trough to trough or from peak to peak, calculated from Hamilton's, our replicated MS model, and BB-RGDP, are all within one quarter of NBER's chronology. 
Another way to measure how closely the turning points determined by two statistical methods are related is to calculate an index of concordance suggested by Harding and Pagan (2002). This index measures the percentage of time two series are in the same phase of expansion or recession simultaneously. Let $S_{x t}=1$ denotes series $x$ in an expansion state at time $t$, and $S_{x t}=0$ denotes series $x$ in a recession state at time $t$. We denote $S_{y t}=1$, and $S_{y t}=0$ similarly for series $y$. The index of concordance (IC) between series $x$ and $y$ is given as:

$$
I C_{x y}=n^{-1}\left\{\sum_{t=1}^{n} S_{x t} S_{y t}+\left(1-S_{x t}\right)\left(1-S_{y t}\right)\right\}
$$

where $n$ is the number of observations. If series $x$ and $y$ are independent, the index of concordance has an expected value of

$$
E\left[I C_{x y}\right]=E\left[S_{x t}\right] E\left[S_{y t}\right]+\left(1-E\left[S_{x t}\right]\right)\left(1-E\left[S_{y t}\right]\right),
$$

where $E\left[S_{x t}\right]=\operatorname{prob}\left(S_{x t}=1\right)$, and can be approximated by the percentage of time that series $x$ is in the expansion state, and $E\left[S_{y t}\right]$ is defined similarly. The null hypothesis is that series $x$ and $y$ are independent. Thus, the estimated index of concordance can be compared to its expected value to determine whether or not there is a statistically significant relationship between the business cycle phases of series $x$ and $y$.

Table 4 shows the indexes of concordance for the turning points determined by the various methods that were reported in Table 2. There are several points to note. First, the indexes of concordance are all statistically significant from zero, and the business cycle phases all appear to be highly synchronized given the high values of the indexes. A word of caution, however, is in order. Note that the expected values of the indexes are also relatively high, up to 0.75 , suggesting that it is possible that two series are in the same phases of a business cycle $75 \%$ of the time, yet the business cycle phases of these two series are independent. Second, BB-RGNP, despite missing a complete recession cycle, nevertheless has a high degree of concordance with the NBER's chronology, and with the turning points determined by Hamilton's and our replicated MS models. Third, the two sets of BB algorithm determined turning points, BB-RGNP and BB-RGDP, do as well as the turning points determined by Hamilton's and our replicated MS models when compared to the NBER's chronology.

Table 5 presents the turnings points for 1947:I - 2011:III for the NBER's chronology and those obtained using the BB algorithm for real GDP (BB-FULL). Before we discuss our results, we want to note 
that the NBER's chronology is reproduced here for this sample period for ease of comparison. Also, since the $\mathrm{BB}$ algorithm is invariant to the sample period, it produces the exact same turning points as those reported in column (5) of Table 2 for the sample period 1951:I -1984:IV. There are two main differences between the turning points found by BB-FULL and the NBER's chronology. First, BB-FULL identified a trough at 1947:III, which is not in the NBER's chronology. Second, BB-FULL did not identify the 2001:I - 2001:IV recession which is in the NBER's chronology. Predictably, the average recession is shorter and the average expansion is longer for BB-FULL than they are for the NBER's chronology as can be seen in Table 6. Nevertheless, the index of concordance between them is 0.92 with an expected value of 0.75 , suggesting a high degree of synchronization between these two series.

To summarize our results so far, we find that Hamilton's MS model is not robust to the sample period and to a slight change in the variable used in the model. In particular, we are unable to obtain meaningful turning points using real GDP rather than real GNP for 1951:I - 1984:IV, and again for 1947:I 2011:III using real GDP. The simpler BB algorithm, on the hand, consistently produces business cycle turning points that are very consistent with the NBER's chronology.

\section{Coincident index}

Burns and Mitchell (1946) and the NBER Committee do not rely on a single economic indicator to date business cycles. Nevertheless, real GDP has emerged as the most popular single economic indicator of quarterly aggregate economic activity. As mentioned in Section II, the Federal Reserve Bank of Philadelphia publishes a monthly coincident index for the U.S. and 50 states. This index is constructed based on a dynamic single-factor model developed by Stock and Watson $(1989,1991)$ using Kalman filter. The index is made up of four economic indicators, three are available monthly, and one is available only quarterly. The monthly indicators are nonagricultural payroll employment, unemployment rate, and average hours worked in manufacturing, while the quarterly indicator is real wage and salary disbursements. The use of this index of four indicators acknowledges the importance of co-movements of several indicators when dating business cycle turning points. Furthermore, since it is available monthly, it has the advantage over the quarterly real GDP in timeliness. Crone (2006) suggested that this index can be used as a composite measure of monthly economic activity. Yet, there are few studies that have examined how well this index could replicate features of the U.S. business cycle. In this section, we compare this 
index to the real GDP, again using the NBER's chronology as the benchmark, to see how well this index could replicate features of the U.S. business cycle for the sample period 1979:01 - 2011:09.

In column (1) of Table 7, we reproduced NBER's monthly chronology for ease of comparison. To be consistent with our quarterly results, we will assume that difference of three months is not significant. Column (2) of Table 7 shows the turning points determined by the BB algorithm using the monthly index (BB-M). Two features stand out. First, BB-M failed to signal the recession of 1981:01 - 1980:07. Second, BB-M signaled the end of the latest recession in 1009:12, six months after the end date of 2009:06 determined by the NBER's Committee. We next convert the monthly index into quarterly index by averaging the three months of the quarter. The turning points obtained by the $\mathrm{BB}$ algorithm and this constructed quarterly index (BB-Q) are shown in column (5). For ease of comparison, columns (3) and (4) are reproduced from Table (5) for the quarterly sample period 1979:I - 2011:III. The turning points determined by BB-Q are almost the same as NBER's chronology except for the most recent recession. NBER's chronology dated the end of the most recent at 2009:II, while BB-Q dated its end at 2009:IV. Note that unlike BB-M, BB-Q did not miss the 1980:I - 1980:III recession. Furthermore, unlike the real GDP, BB-Q also did not miss the 2001:I - 2002:I recession.

Measures of durations are shown in Table 8. As expected, there are differences in the duration measures due especially to the failure of BB-M to signal the recession of 1980:01 - 1980:07 as can be seen in columns (1) and (2). Columns (3), (4), and (5) show the duration measures in quarters. Because the recession of 2001:I - 2001:IV was missed by the real GDP, its turning points produced rather different average duration measures when compared to the NBER's chronology. The differences are greater in average durations than in cycle length. For example, complete cycle, measured from trough to trough, totaled 115 quarters for both the NBER's chronology and the turning points found using real GDP. The average cycles are 28.75 quarters and 38.33 quarters, respectively, however. Similar pattern can be seen in complete cycle measured from peak to peak. BB-Q's duration measures, on the other hand, are very close to those of the NBER's chronology.

Table 9 reports the indexes of concordance of business cycle phases determined and reported in Table 7. We see that there is a high degree of concordance among all the various business cycle phases, 
suggesting that the business cycle features are much more similar than may be suggested by the duration statistics.

The results of this section show once again that the BB algorithm can replicate the U.S. business cycle features quite well. It also shows that the coincident index is quite a capable indicator of aggregate economic activity. The quarterly index appeared to be slightly better than the monthly index since it did not miss the recession of 1980:01 - 1980:07 (NBER's monthly chronology). It is also better than using the BB algorithm with real GDP since it did not miss the recession of 2001:I - 2001:V. However, this presents a slight dilemma since there appears to be a trade-off between accuracy and timeliness. The quarterly index is slightly more accurate but less timely than the monthly index, the indexes of concordance with NBER's chronology are the same at $95 \%$ for both the quarterly and monthly indexes, however. We believe that both the monthly and quarterly indexes should be used together. For example, the monthly index could be monitored closely for signals of the direction of the economy, but should not be a signal for the need for policy changes until a clearer picture emerges from the quarterly index.

VI. Summary and conclusions

We investigated two issues in business cycle research in this paper. First, can the more complicated parametric MS models of Hamilton replicate the U.S. business cycle features better than the simpler non-parametric approach of the BB algorithm? Second, how good is the monthly coincident index, published by the Federal Reserve Bank of Philadelphia, as an indicator of aggregate economic activity when compared to the real GDP? Throughout, NBER's chronology is the benchmark for comparison based on criteria such as dating of turning points, duration measures, and index of concordance. On the first question, our results support the use of the BB algorithm over Hamilton's MS model. We are unable to replicate Hamilton's results when we used a different sample period than his original sample period, and when we used the same sample period but substituted real GDP for real GNP, even-though the correlation coefficient between real GDP and real GNP is 0.99 and 0.94 between the growth rates of these two series for that sample period. This is the first time this has been demonstrated in the literature to our knowledge. The BB algorithm, although not perfect, did a very good job of replicating many features of the U.S. business cycle. In addition, the BB algorithm is easy to implement, is time invariant, and requires far fewer assumptions and restrictions than the MS model. The BB algorithm is also arguably more transparent, 
involves less subjective judgments and is more consistent than the NBER's Committee. The latter two points stem from the fact that when there is a committee member change, the incoming members may not hold the same beliefs as the outgoing members. In sum, there is much to recommend the BB algorithm over the MS model in business cycle research.

The monthly coincident index published by the Federal Reserve Bank of Philadelphia has proven to be a very capable indicator of U.S. aggregate economic activity. The constructed quarterly index appears to be slightly better than the monthly index. In our sample period, it was able to determine all the turning points including the recession missed by the monthly index and the one missed by the quarterly real GDP. The most interesting result is that both the monthly and the constructed quarterly indexes signaled the end of the most recent recession six months or two quarters later than NBER's chronology. The constructed quarterly index is more accurate but less timely than the monthly index. We suggest that the monthly index could be used to monitor but not to signal a change in policy stance, which could be left to the constructed quarterly index. 


\section{Data Sources}

NBER chronology: Downloaded from http://www.nber.org/cycles/cyclesmain.html on May 14, 2012.

Real GNP: Obtained from the data file (gnpdata.prn) included with RATS, version 8.1.

Real GDP: Downloaded from the website of U.S. Department of Commerce, Bureau of Economic Analysis www.bea.gov on August 1, 2012.

U.S. coincident index: downloaded from the website of the Federal Reserve Bank of Philadelphia http://www.philadelphiafed.org/research-and-data/regional-economy/indexes/coincident/ on November 16, 2011. 


\section{References}

Boldin, Michael D., 1994. Dating turning points in the business cycle. Journal of Business 67, 97-131.

Bruno, Giancarlo, Otranto, Edoardo, 2008. Models to date the business cycle: The Italian case. Economic Modelling 25, 899-911.

Bry, G. Boschan, C., 1971. Cyclical analysis of time series: Selected procedures and computer programs. National Bureau of Economic Research, New York.

Burns, A. F., Mitchell, W. C., 1946. Measuring business cycles. National Bureau of Economic Research, New York.

Crone, Theodore M., 2006. What a new set of indexes tell us about state and national business cycles.

Business Review, Federal Reserve Bank of Philadelphia, 11-24.

Crone, Theodore M., Clayton-Matthews, A., 2005. Consistent economic indexes for the 50 states. The Review of Economics and Statistics 87, 593-603.

Filardo, Andrew J., 1994. Business-cycle phases and their transitional dynamics. Journal of Business \& Economic Statistics 12, 299-308.

Hamilton, James D., 1989. A new approach to the economic analysis of nonstationary time series and the business cycle. Econometrica 57, (2), 357-384.

Hamilton, James D., 1994. Time series analysis. Princeton University Press, Princeton, NJ.

Hamilton, James D., 2003. Comment on "A comparison of two business cycle dating methods". Journal of Economic Dynamics and Control 27, 1691-1693.

Harding, D., Pagan, A., 2002. Dissecting the cycle: A methodological investigation. Journal of Monetary Economics 49, 365-381.

Harding, D., Pagan, A., 2003a. A comparison of two business cycle dating methods. Journal of Economic Dynamics and Control 27, 1681-1698.

Harding, D., Pagan, A., 2003b. Rejoinder to James Hamilton. Journal of Economic Dynamics and Control 27, 1695-1690.

Hess, G. D., Iwata, S., 1997. Measuring and comparing business-cycle features. Journal of Business \& Economic Statistics 15, 432-444.

Kim, Chang-Jin, Nelson, Charles R., 1998. Business cycle turning points, a new coincident index, and tests of duration dependence based on a dynamic factor model with regime switching. The Review of Economics and Statistics 80, 188-201.

Krolzig, Hans-Martin, Toro, J., 2005. Classical and modern business cycle measurements: The European case. Spanish Economic Review 7, 1-12.

Massmann, Michael, Mitchell, J. Weale, M., 2003. Business cycles and turning points: A survey of statistical techniques. National Institute Economic Review, 90-106.

Mejía-Reyes, Pablo, 2004. Classical business cycles in America: Are national business cycles synchronized? International Journal of Applied Econometrics and Quantitative Studies, 1-3, 75-102. 
McAdam, Peter, 2007. USA, Japan, and the Euro Area: Comparing business-cycle features. International Review of Applied Economics 21, 135-156.

Mönch, Emanuel, Uhlig, Harald, 2005. Towards a monthly business cycle chronology for the Euro area. SFB 649, Humboldt-Universität zu Berlin, Berlin.

NBER Webpage http://www.nber.org/cycles/cyclesmain.html.

Proietti, Tommaso, 2005. New algorithms for dating the business cycle. Computational Statistics \& Data Analysis 49, 477-498.

RATS, version 8.0, 2010. Estima, Evanston, IL.

Schirwitz, Beate, 2009. A comprehensive German business cycle chronology. Empirical Economics 37, 287-301.

Stock, James H., Watson, Mark S., 1989. New Indexes of coincident and leading economic indicators. NBER Macroeconomics Annual, 351-394.

Stock, James H., Watson, Mark S., 1991. A probability model of the coincident economics indicators, in Lahiri, K., Moore, G. H., ed., Leading Economic Indicators: New Approaches and Forecasting Records, (Cambridge University Press, Cambridge) 63-89. 
1. There are a few exceptions. For example, in Italy, Istituto di Studi ed Analisi Economica (ISAE) provides business cycle turning points for the Italian economy. The Centre for Economic Policy Research (CEPR) based in London, provides turning points for the 11 original euro area member countries from 1970 to 1998, and the euro area as a whole since 1999.

2. See the interesting exchange between Hamilton (2003), and Harding and Pagan (2003b).

3. Two points should be noted here. First, this is exactly the criticism and concern expressed by many researchers that the MS models in general are not very robust. Second, Krolzig and Toro (2005) did not argue that the Markov-switching VAR is better than the BB algorithm in replicating features of the European business cycles.

4. This is akin to the use of the popular "Taylor rule" to approximate the decision outcomes of the Federal Open Market Committee.

5. This comparison was done recently in a paper by Harding and Pagan (2003a). Our paper differs from theirs in a few significant ways. First, they approximated Hamilton's MS model with a Kalman filter. We provide a comparison by estimating Hamilton's MS model using different measures of aggregate economic activity and over different sample periods. Second, we also provide a comparison of real GDP to a coincident index to determine which is a better single indicator of aggregate economic activity.

6. Hamilton's MS model is used for comparison for several reasons. First, there are many extensions to the original MS model. Research by Filardo (1994) who estimated a MS model with time-varying transition probabilities; Kim and Nelson (1998) who estimated a MS model in a Bayesian framework; and Krolzig and Toro (2005) who estimated a MS-VAR model are just a few examples of a rather large body of literature. Because of this, it is not clear which version of the model is the most appropriate one to use. Second, Hamilton's MS model is the one used most frequently when comparing different statistical models in their ability to replicate business cycle features. There are also extensions made to the BB algorithm. Examples are Mönch and Uhlig (2005) who supplemented the BB algorithm with a combined amplitude/phase-length criterion which would retain cycle phases that are short but pronounced which otherwise would have been excluded by the BB algorithm, and Proietti (2005) who combined a modified BB algorithm with a Markov chain algorithm to identify turning points. We use the Bry and Boschan (1971) version of the algorithm to be consistent with our use of Hamilton's MS model.

7. Quoted from the NBER's website http://www.nber.org/cycles/cyclesmain.html.

8. There is a publication lag of several weeks of the latest data. For example, the coincident index for April is published in May.

9. We used a maximum likelihood estimation routine and using a data file (gnpdata.prn) provided in version 8.0 of RATS.

10. Real GDP data are downloaded from the website of Bureau of Economic Analysis, Department of Commerce at www.bea.gov.

11. Some earlier readers of this paper have suggested that the longer sample period includes the period of the Great Moderation starting roughly in the middle of the 1980s. Thus, the MS model should also allow for a decline in the variance of the output growth rate. But again, this is exactly the issue addressed in this paper that the MS model is not a very robust model, and other simpler and more robust method of dating business cycle is available.

12. The source of this information is NBER's website http://www.nber.org/cycles/cyclesmain.html. 
13. We are rather surprised by this result. But we know that this is not because we are using different estimation technique or software since we are able to replicate Hamilton's original results quite closely. We have re-estimated the MS model using real GNP and real GDP several times using different starting values. Each time, we obtained identical results to those reported in this paper. Thus, the only source of difference between the two sets of results is the use of real GNP in one case, and real GDP in the other. We have not tried to investigate how the use of two seemingly very similar time series can give rise to such different results since it is beyond the scope of this paper. But we note that from the results in columns (2) and (3) of Table 1, the two time series behaved quite differently in the MS model and also interacted differently with the other estimated parameters in the MS model.

14. The modified BB algorithm is commonly referred to as BBQ.

15. The BB algorithm is modified for use with quarterly data as suggested in Harding and Pagan (2002).

16. The difference in results is greater for these two series using the MS models, however. 
Table 1: Markov-switching Models

\begin{tabular}{c|c|c|c|c}
\hline \hline & $(1)$ & $(2)$ & $(3)$ & $(4)$ \\
\hline \multirow{2}{*}{ Parameter } & Hamilton & Replicated & Real GDP & Real GDP \\
\hline$\alpha_{1}$ & 1.522 & 1.164 & 0.965 & 0.909 \\
& $(0.264)$ & $(0.076)$ & $(0.177)$ & $(0.082)$ \\
$\alpha_{0}$ & -0.358 & -0.359 & -1.034 & -1.310 \\
& $(0.265)$ & $(0.254)$ & $(0.835)$ & $(0.274)$ \\
$p$ & 0.905 & 0.904 & 0.946 & 0.958 \\
& $(0.037)$ & $(0.039)$ & $(0.067)$ & $(0.016)$ \\
$q$ & 0.755 & 0.755 & 0.169 & 0.299 \\
& $(0.097)$ & $(0.097)$ & $(0.386)$ & $(0.149)$ \\
$\sigma$ & 0.769 & 0.769 & 0.932 & 0.752 \\
& $(0.067)$ & $(0.070)$ & $(0.107)$ & $(0.040)$ \\
$\phi_{1}$ & 0.014 & 0.013 & 0.343 & 0.428 \\
& $(0.120)$ & $(0.128)$ & $(0.106)$ & $(0.069)$ \\
$\phi_{2}$ & -0.058 & -0.058 & 0.089 & 0.248 \\
& $(0.137)$ & $(0.136)$ & $(0.120)$ & $(0.065)$ \\
$\phi_{3}$ & -0.247 & -0.247 & -0.090 & -0.216 \\
& $(0.107)$ & $(0.110)$ & $(0.120)$ & $(0.076)$ \\
$\phi_{4}$ & -0.213 & -0.213 & -0.164 & -0.099 \\
$E\left(D_{R}\right)$ & $(0.110)$ & $(0.118)$ & $(0.103)$ & $(0.069)$ \\
$E\left(D_{E}\right)$ & 10.082 & 4.082 & 1.203 & 1.427 \\
\hline \hline
\end{tabular}

Note: asymptotic standard errors are in parentheses below the estimates. 
Table 2: Business cycle turning points, 1951:I - 1984:IV

\begin{tabular}{|c|c|c|c|c|c|c|c|c|c|}
\hline \multicolumn{2}{|c|}{ (1) } & \multicolumn{2}{|c|}{ (2) } & \multicolumn{2}{|c|}{ (3) } & \multicolumn{2}{|c|}{ (4) } & \multicolumn{2}{|c|}{ (5) } \\
\hline \multicolumn{2}{|c|}{ NBER } & \multicolumn{2}{|c|}{ Hamilton } & \multicolumn{2}{|c|}{ Replicated } & \multicolumn{2}{|c|}{ BB-RGNP } & \multicolumn{2}{|c|}{ BB-RGDP } \\
\hline Peak & Trough & Peak & Trough & Peak & Trough & Peak & Trough & Peak & Trough \\
\hline 1953:III & 1954:II & 1953:III & 1954:II & 1953:III & 1954:II & 1953:II & 1954:II & 1953:II & 1954:I \\
\hline 1957:III & 1958:II & 1957:I & 1958:I & 1957:I & 1958:II & 1957:III & 1958:I & 1957:III & 1958:I \\
\hline 1960:II & 1961:I & 1960:II & 1960:IV & 1960:I & 1960:IV & 1960:I & 1960:IV & 1960:I & 1960:IV \\
\hline 1969:IV & 1970:IV & 1969:III & 1970:IV & 1969:III & 1970:IV & 1969:III & 1970:II & 1969:III & 1970:I \\
\hline 1973:IV & 1975:I & 1974:I & 1975:I & 1973:IV & 1975:I & 1973:IV & 1975:I & 1973:IV & 1975:I \\
\hline 1980:I & 1980:III & 1979:II & 1980:III & 1979:III & 1980:III & & & 1980:I & 1980:III \\
\hline 1981:III & 1982:IV & 1981:II & 1982:IV & 1981:I & 1982:IV & 1981:III & 1982:III & 1981:III & 1982:I \\
\hline
\end{tabular}

Notes: Column 1 is NBER's chronology. Columns 2 and 3 are turning points from the MS models, and column 4 and 5 are turning points estimated using the BB algorithm.

Table 3: Duration and average duration in quarters

\begin{tabular}{l|c|c|c|c|c}
\hline \hline & $(1)$ & $(2)$ & $(3)$ & $(4)$ & $(5)$ \\
\cline { 2 - 6 } & NBER & Hamilton & Replicated & BB-RGNP & BB-RGDP \\
\hline Recession & 25 & 29 & 32 & 21 & 19 \\
(Peak to Trough) & $(3.57)$ & $(4.14)$ & $(4.57)$ & $(3.50)$ & $(2.71)$ \\
Expansion & 92 & 88 & 85 & 96 & 96 \\
(Trough to Peak) & $(15.33)$ & $(14.67)$ & $(14.17)$ & $(19.20)$ & $(16.00)$ \\
Trough to Trough & 114 & 114 & 114 & 113 & 112 \\
& $(19.00)$ & $(19.00)$ & $(19.00)$ & $(22.60)$ & $(18.67)$ \\
Peak to Peak & 112 & 111 & 112 & 113 & 113 \\
& $(18.67)$ & $(18.50)$ & $(18.67)$ & $(22.60)$ & $(18.83)$ \\
\hline \hline
\end{tabular}

Note: The top number is duration in quarters and the bottom number in parenthesis is average duration in quarters. 
Table 4: Concordance Index

\begin{tabular}{c|c|c|c|c|c}
\hline \hline & NBER & Hamilton & Replicated & BB-RGNP & BB-RGDP \\
\hline NBER & 1.00 & & & \\
Hamilton & 0.92 & 1.00 & & \\
& $(0.68)$ & & & \\
Replicated & 0.93 & 0.96 & 1.00 & & \\
& $(0.66)$ & $(0.65)$ & & \\
BB-RGNP & 0.93 & 0.90 & 0.90 & 1.00 & \\
& $(0.71)$ & $(0.70)$ & $(0.68)$ & & \\
BB-RGDP & 0.92 & 0.88 & 0.89 & 0.96 & \\
& $(0.72)$ & $(0.71)$ & $(0.69)$ & $(0.75)$ & \\
\hline \hline
\end{tabular}

Note: The number in parenthesis is the expected value. 
Table 5: Business cycle turning points, 1947:I - 2011:III

\begin{tabular}{|c|c|c|c|}
\hline \multicolumn{2}{|c|}{ NBER } & \multicolumn{2}{|c|}{ BB - FULL } \\
\hline Peak & Trough & Peak & Trough \\
\hline & & & 1947:III \\
\hline 1948:IV & 1949:IV & 1948:IV & 1949:II \\
\hline 1953:III & 1954:II & 1953:II & 1954:I \\
\hline 1957:III & 1958:II & 1957:III & 1958:I \\
\hline 1960:II & 1961:I & 1960:I & 1960:IV \\
\hline 1969:IV & 1970:IV & 1969:III & 1970:I \\
\hline 1973:IV & 1975:I & 1973:IV & 1975:I \\
\hline 1980:I & 1980:III & 1980:I & 1980:III \\
\hline 1981:III & 1982:IV & 1981:III & 1982:I \\
\hline 1990:III & 1991:I & 1990:II & 1991:I \\
\hline 2001:I & 2001:IV & & \\
\hline 2007:IV & 2009:II & 2007:IV & 2009:II \\
\hline
\end{tabular}

Table 6: Duration and average durations for 1947:I - 2011:III

\begin{tabular}{l|c|c}
\hline \hline & NBER & BB - FULL \\
\hline Recession & 40 & 30 \\
(Peak to Trough) & $(3.64)$ & $(3.00)$ \\
Expansion & 202 & 217 \\
(Trough to Peak) & $(20.20)$ & $(21.70)$ \\
Trough to Trough & 238 & 247 \\
& $(23.80)$ & $(24.70)$ \\
Peak to Peak & 236 & 236 \\
& $(23.60)$ & $(26.22)$ \\
\hline \hline
\end{tabular}

Note: See note to Table 3. 
Table 7: Business cycle turning points

\begin{tabular}{|c|c|c|c|c|c|c|c|c|c|}
\hline \multicolumn{2}{|c|}{ (1) } & \multicolumn{2}{|c|}{ (2) } & \multicolumn{2}{|c|}{ (3) } & \multicolumn{2}{|c|}{ (4) } & \multicolumn{2}{|c|}{ (5) } \\
\hline \multicolumn{2}{|c|}{ Monthly NBER } & \multicolumn{2}{|c|}{ BB-M } & \multicolumn{2}{|c|}{ Quarterly NBER } & \multicolumn{2}{|c|}{ Quarterly Real GDP } & \multicolumn{2}{|c|}{ BB-Q } \\
\hline Peak & Trough & Peak & Trough & Peak & Trough & Peak & Trough & Peak & Trough \\
\hline 1980:01 & 1980:07 & & & 1980:I & 1980:III & 1980:I & 1980:III & 1980:I & 1980:III \\
\hline 1981:07 & 1982:11 & 1981:07 & 1982:11 & 1981:III & 1982:IV & 1981:III & 1982:I & 1981:III & 1982:IV \\
\hline 1990:07 & 1991:03 & 1990:06 & 1991:05 & 1990:III & 1991:I & 1990:II & 1991:I & 1990:II & 1991:II \\
\hline 2001:03 & 2001:11 & 2001:03 & 2002:02 & 2001:I & 2001:IV & & & 2001:I & 2002:I \\
\hline $2007: 12$ & 2009:06 & 2008:01 & 2009:12 & 2007:IV & 2009:II & 2007:IV & 2009:II & 2008:I & 2009:IV \\
\hline
\end{tabular}

Note: The sample period is 1979:1 - 2011:9.

Table 8: Duration measures for sample period 1979:1 - 2011:9

\begin{tabular}{l|c|c|c|c|c}
\hline \hline & $(1)$ & $(2)$ & $(3)$ & $(4)$ & $(5)$ \\
\cline { 2 - 5 } & Monthly NBER & BB-M & Quarterly NBER & Quarterly Real GDP & BB-Q \\
\hline $\begin{array}{l}\text { Recession } \\
\text { (Peak to Trough) }\end{array}$ & 56 & 61 & 18 & 13 & $(3.25)$ \\
& $(11.20)$ & $(15.25)$ & $(3.60)$ & 104 & $(4.40)$ \\
Expansion & 297 & 280 & 99 & $(34.67)$ & $(24.25)$ \\
(Trough to Peak) & $(74.25)$ & $(93.33)$ & $(24.75)$ & 115 & 117 \\
Trough to Trough & 347 & 325 & 115 & $(38.33)$ & $(29.25)$ \\
& $(86.75)$ & $(108.33)$ & $(28.75)$ & 111 & $(37.00)$ \\
Peak to Peak & 335 & 318 & 111 & $(28.00)$ \\
\hline \hline
\end{tabular}

Note: See note to Table 3. 
Table 9: Concordance index and coincident index

\begin{tabular}{|c|c|c|c|c|c|}
\hline & $\begin{array}{c}\text { Monthly } \\
\text { NBER }\end{array}$ & BB-M & $\begin{array}{c}\text { Quarterly } \\
\text { NBER }\end{array}$ & $\begin{array}{l}\text { Quarterly } \\
\text { Real GDP }\end{array}$ & BB-Q \\
\hline $\begin{array}{l}\text { Monthly } \\
\text { NBER }\end{array}$ & 1.00 & & & & \\
\hline BB-M & $\begin{array}{c}0.95 \\
(0.75)\end{array}$ & 1.00 & & & \\
\hline $\begin{array}{c}\text { Quarterly } \\
\text { NBER }\end{array}$ & $\mathrm{n} / \mathrm{a}$ & $\mathrm{n} / \mathrm{a}$ & 1.00 & & \\
\hline $\begin{array}{l}\text { Quarterly } \\
\text { Real GDP }\end{array}$ & $\mathrm{n} / \mathrm{a}$ & $\mathrm{n} / \mathrm{a}$ & $\begin{array}{c}0.95 \\
(0.79)\end{array}$ & 1.00 & \\
\hline BB-Q & $\mathrm{n} / \mathrm{a}$ & $\mathrm{n} / \mathrm{a}$ & $\begin{array}{c}0.95 \\
(0.74)\end{array}$ & $\begin{array}{c}0.92 \\
(0.77)\end{array}$ & 1.00 \\
\hline
\end{tabular}

Note: $\mathrm{n} / \mathrm{a}=$ not applicable. The number in parenthesis is the expected value. 